\title{
A GIS-based modeling of snow accumulation and melt processes in the Votkinsk reservoir basin
}

\author{
Sergey V. PYANKOV ${ }^{1}$, Andrey N. SHIKHOV ${ }^{1}$, Nikolay A. KALININ ${ }^{2}$, \\ Eugene M. SVIYAZOV ${ }^{2}$
}

1. Department of Cartography and Geoinformatics, Perm State University, 15 Bukireva Street, 614990 Perm, Russia;

2. Department of Meteorology and Atmosphere Protection, Perm State University, 15 Bukireva Street, 614990 Perm, Russia

\begin{abstract}
Coupled hydrological and atmospheric modeling is an efficient method for snowmelt runoff forecast in large basins. We use short-range precipitation forecasts of mesoscale atmospheric Weather Research and Forecasting (WRF) model combining them with ground-based and satellite observations for modeling snow accumulation and snowmelt processes in the Votkinsk reservoir basin $\left(184,319 \mathrm{~km}^{2}\right)$. The method is tested during three winter seasons (2012-2015). The MODIS-based vegetation map and leaf area index data are used to calculate the snowmelt intensity and snow evaporation in the studied basin. The GIS-based snow accumulation and snowmelt modeling provides a reliable and highly detailed spatial distribution for snow water equivalent (SWE) and snow-covered areas (SCA). The modelling results are validated by comparing actual and estimated SWE and SCA data. The actual SCA results are derived from MODIS satellite data. The algorithm for assessing the SCA by MODIS data (ATBD-MOD 10) has been adapted to a forest zone. In general, the proposed method provides satisfactory results for maximum SWE calculations. The calculation accuracy is slightly degraded during snowmelt periods. The SCA data is simulated with a higher reliability than the SWE data. The differences between the simulated and actual SWE may be explained by the overestimation of the WRF-simulated total precipitation and the unrepresentativeness of the SWE measurements (snow survey).
\end{abstract}

Keywords: snow accumulation and snowmelt processes; snow water equivalent; GIS-based modeling; WRF-ARW model

\section{Introduction}

A river's hydrological regime in a cold climate zone is mainly determined by snow accumulation and snowmelt processes, because the snowmelt runoff forms $60-70 \%$ of the annual streamflow. Snowmelt floods are often observed during the spring snowmelt season and they cause considerable damage. The reliability of their forecasting is not satisfactory in some cases. To increase the forecast reliability, it is necessary to evaluate the snow water equiva-

Received: 2016-10-11 Accepted: 2017-02-24

Foundation: RFBR project 14-05-00317-a

Author: Andrey N. Shikhov, Associate Professor, E-mail: Russia shikhovan@gmail.com 
lent (SWE) more accurately, considering the heterogeneity of its spatial distribution. This heterogeneity is determined by the interaction between snow accumulation, snowmelt, snow sublimation and blowing processes (Kuzmin, 1961; Pomeroy et al., 1998). Therefore, the SWE calculation has a high uncertainty, especially in mountainous terrain with sparse observation networks.

Several physically-based models of snow accumulation and melt processes have been developed to calculate the SWE spatial distribution (Tarboton et al., 1996; Marks et al., 1999; Kuchment et al., 2000; Garen and Marks, 2005; Lehning et al., 2006; Quéno et al., 2016). Furthermore, statistical methods based on interpolation may be used to estimate the spatial distribution of the SWE (Carroll and Cressie, 1996; Shutov, 1998; Lopez-Moreno and Nogues-Bravo, 2006). The physically-based models of snow accumulation and melting processes are based on the solution of balance equations in grid cells. Significant volumes and low accessibility of input data, especially for large and ungauged basins, are the limitations for the use of physically-based models. Another restriction is due to the sparse and unrepresentative location of weather stations (Lehning et al., 2006). Due to these reasons, the physically-based models of snow accumulation and snowmelt processes are rarely used in large watersheds (Marks et al., 1999; Garen and Marks, 2005; Kuchment et al., 2010).

Geostatistical methods for SWE estimation are also widely applied in hydrological forecasting. For example, the U.S. National Weather Service uses the results of geostatistical simulation for assessing snow cover characteristics as the input data for a streamflow formation model (Carroll and Cressie, 1996). Given the high density of snow observation networks, an interpolation with an inverse distance weighting method and kriging or regression models are used to simulate snow depth and the SWE. The SWE assessment using regression models based on their dependence on elevation, terrain slope and solar radiation is usually considered to be the most reliable (Elder et al., 1998; Erxleben et al., 2002, Lopez-Moreno and Nogues-Bravo, 2006).

Simultaneously, the estimates of the SWE spatial distribution using ground-based observations also have limited utility over large areas. The spatial density of operational ground-based snow observations is too low to resolve small-scale variability in the SWE distribution as the distance between observations is far greater than the correlation-length scale (Bl"oschl, 1999). This small-scale variability in the SWE distribution is due to orography and vegetation cover diversity (Bl"oschl, 1999). The correct interpolation of SWE field measurement data is impossible in mountainous areas. Interpolation of the accumulated precipitation during the cold period provides more reliable input data for SWE estimation (Shutov, 1998).

The use of mesoscale weather forecast models significantly simplifies the SWE assessment (as well as others meteorological variables) in the cases where ground-based observations are absent (Kunstmann and Stadler, 2005; Georgakakos et al., 2014, Queno et al., 2016). The high reliability and spatial resolution of short-range precipitation forecasts in the cold season allow them to be combining with runoff formation models. The hydrological model is driven by the forecast data obtained from an atmospheric model. As a result, the lead time for runoff forecast significantly increases. Such systems of coupled atmospheric-hydrological forecasts are developed for mountain areas with high flood risk to help 
decision making and reduce the possible damage caused by floods (Addor et al., 2011, Verbunt et al., 2006; Zhao et al., 2009), as well as to calculate water inflow to reservoirs (Georgakakos et al., 2014).

Some snow cover characteristics (the snow-covered area, snow surface temperature and SWE) can be estimated by satellite data. However, the potential of satellite snow data is limited by a number of environmental factors (cloudiness, land cover type, terrain peculiarities and so on). Cloudiness creates a discontinuity in the spatial distribution and in time data series. Dense forest vegetation complicates snow cover identification and mapping due to snow interception and the ability to mask snow cover on the forest floor. The accuracy of satellite measurements of SWE significantly depends on the snow properties, especially the amount of liquid water (Kuchment et al., 2010).

The snow-covered area (SCA) can be estimated most reliably using remote sensing data. Its reliability is determined by Moderate Resolution Imaging Spectroradiometer (MODIS) satellite data ranging from $90 \%$ to $98 \%$ depending on the season and surface type (Hall and Riggs, 2007). Satellite-derived SCA are used for validation and calibration of the physically-based (distributed) models of snow cover (Kuchment et al., 2010)

Estimates of SWE spatial distribution can be also obtained using AMSR-E/Aqua microwave radiometer sounding data. The probable error for SWE assessment based on AMSR-E satellite data is $\sim 25 \%$ (Chang and Rango, 2000), although it may be significantly higher for forest areas. The evaluation results of this algorithm for the European part of Russia have revealed that errors of SWE estimates can reach $200 \%$ (Nosenko et al., 2006).

Thus, the problem of SWE estimation on large watersheds with diverse environments and sparse observation networks has not been solved yet. The present work provides the results of GIS-based modelling of snow cover characteristics in a large basin. The model input is the combination of ground-based, satellite observations and mesoscale numerical weather forecast data. ESRI ArcGis 10.1 software is used for the calculations. The presented technique was applied to the area including the Votkinsk Reservoir catchment $\left(\mathrm{S}=184319 \mathrm{~km}^{2}\right)$. The studied basin is characterised by diverse natural conditions and the sparse location of ground-based weather stations (Figure 1). The simulation period includes the 2012-2015 winter seasons.

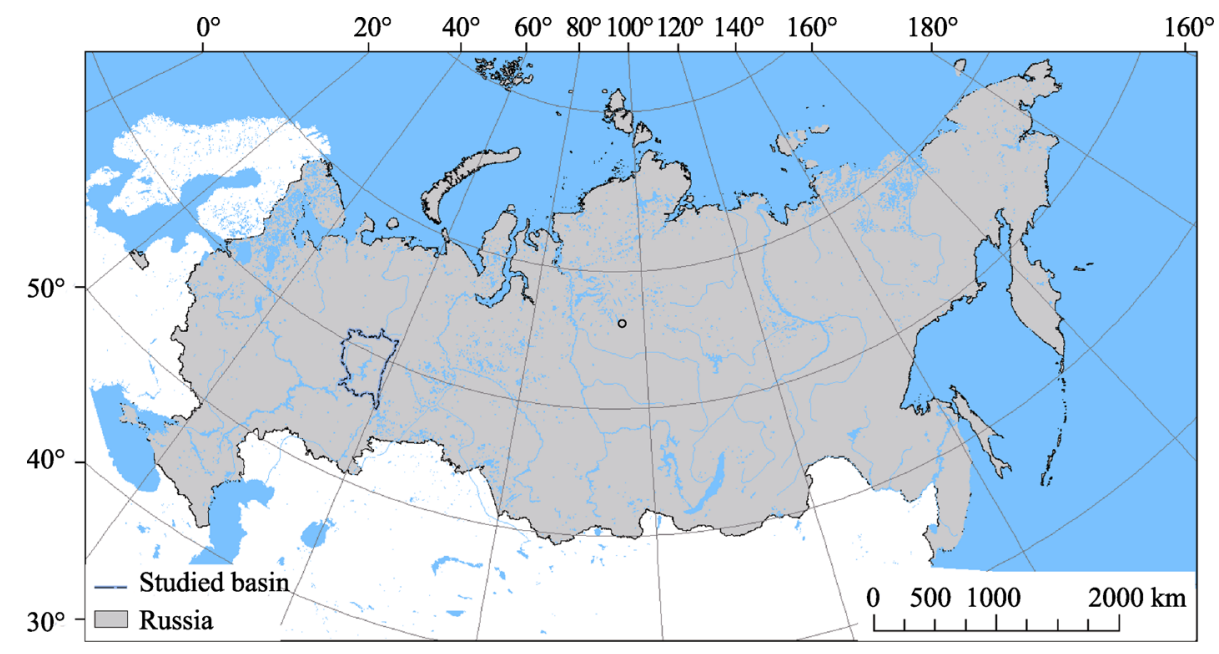

Figure 1 The geographical location of the Votkinsk reservoir basin in Russia 


\section{Study area}

The Votkinsk Reservoir basin is located in the north-eastern part of the Volga river basin, and has an area of $184319 \mathrm{~km}^{2}$ (Figure 1). The minimum elevation within the studied basin is $89 \mathrm{~m}$, and the maximum elevation is $1519 \mathrm{~m}$. The western and central parts of the studied basin belong to the East-European plain with the altitude from $88 \mathrm{~m}$ up to $446 \mathrm{~m}$ in height. The eastern part of the studied basin is located in the Ural Mountain system and is subdivided into the Northern and Middle Ural. The typical point elevation for the Middle Ural is 400-900 $\mathrm{m}$ in height and it increases up to 800-1519 $\mathrm{m}$ in height for the Northern Ural. Approximately $70 \%$ of the studied area is covered by forests. The recovered mixed spruce-birch forest prevails in most of the watershed. The undisturbed dark coniferous forests cover significant areas north of $60^{\circ} \mathrm{N}$, and the recovered small-leaved forests prevail in the southern part of the basin (Figure 2).

The climate of the studied catchment is temperate-continental and characterised by long and cold winters. Annual precipitation ranges from $500 \mathrm{~mm}$ in the southwest part of the basin to $900-1100 \mathrm{~mm}$ in the mountainous north-eastern areas. During the cold season (from November to March), the total precipitation ranges from 150-200 $\mathrm{mm}$ in the flat part of the basin up to 300-350 mm in the mountains. Snow cover usually forms in the middle of October in the mountainous areas, and in early November in the flat part of the basin. It melts in the middle of April for the plain part and at the beginning of May for the mountainous part. The maximum snow depth and SWE forms in the end of March. It ranges usually ranges from $50-60 \mathrm{~cm}$ in the southwestern part of the basin to $120 \mathrm{~cm}$ in the mountainous north-eastern areas. The maximum SWE ranges from 130-180 $\mathrm{mm}$ at the plain part of the watershed and 200-250 $\mathrm{mm}$ at the uplands to $\sim 300 \mathrm{~mm}$ and even higher in the northeastern areas.

\section{Data collection and methods}

\subsection{Data sources}

The methodology of SWE assessment is based on the summing of cold period precipitation, considering their phases, snowmelt during thaws, snow interception and sublimation from the snow surface. Spring snowmelt intensity is assessed according to the method of Kuzmin, which is based on the snow cover heat balance equation when the melting snow surface temperature is $0^{\circ} \mathrm{C}$ (Kuzmin, 1961). The snow cover characteristics are calculated with a 24 $\mathrm{h}$ time step and $3000 \mathrm{~m}$ spatial resolution. Calculations with a higher grid step are not appropriate. The input data used for modelling is as follows:

- Forecast fields of solid and liquid precipitations, wind speed at $10 \mathrm{~m}$ height, temperature and air humidity at $850 \mathrm{hPa}$ isobaric surface, computed by the mesoscale weather forecast model WRF with $10 \mathrm{~km}$ grid step;

- Observations data from 34 ground-based weather stations located both at the studied watershed and outside it (air temperature and humidity, total and lower cloudiness, daily total precipitations);

- Underlying surface data: the digital elevation model of the watershed based on the 
GMTED2010 elevation matrix (Figure 2a) and an actual land cover map based on Terra/ Aqua MODIS satellite images (Figure 2b);

- SWE field measurement (snow survey) data from the weather stations, to validate the SWE simulation results, and MODIS-estimated snow-covered area during spring snowmelt seasons.
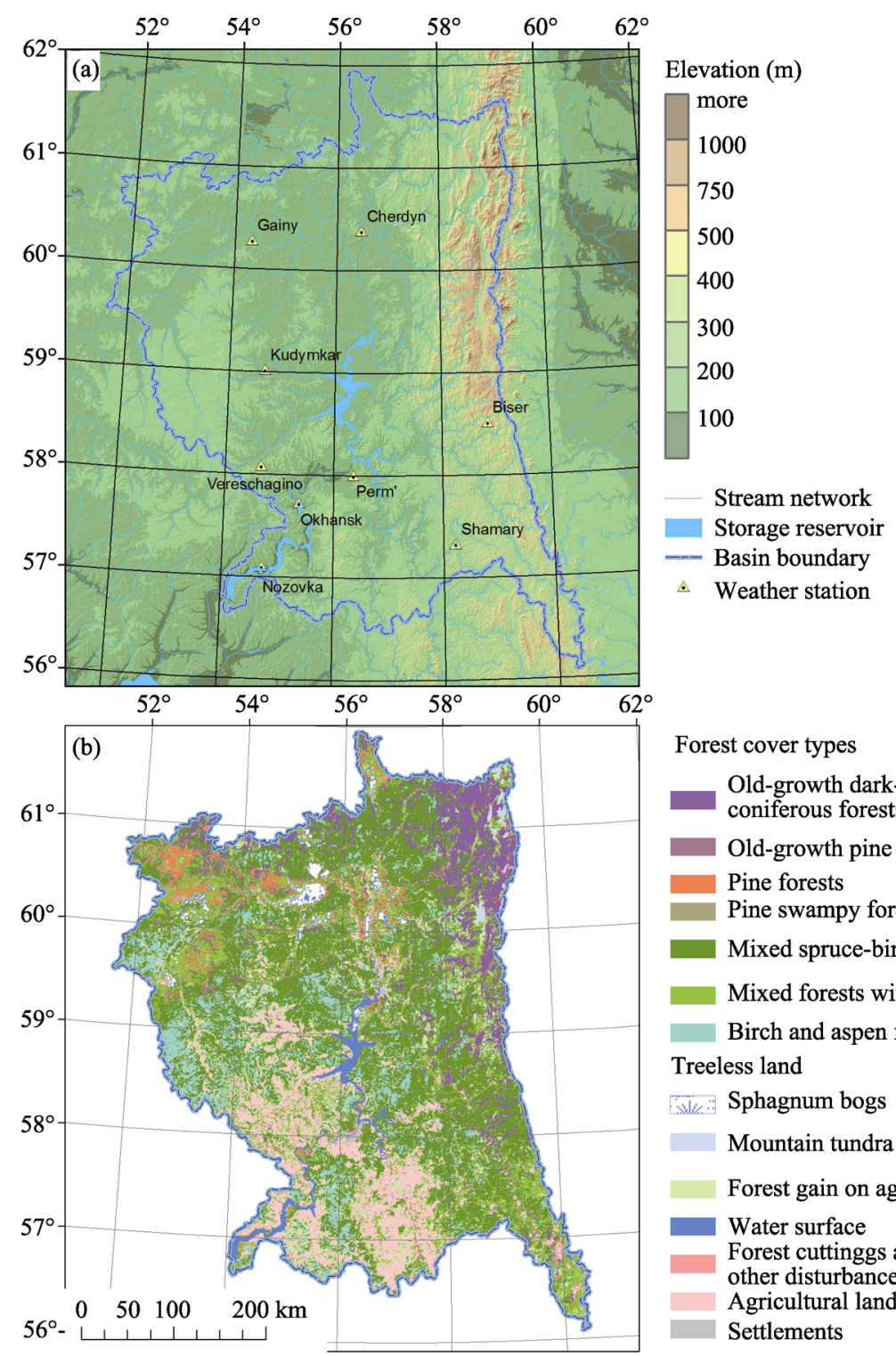

Forest cover types
Old-growth dark-
coniferous forests
Old-growth pine and fir forests
Pine forests
Pine swampy forests
Mixed spruce-birch forests
Mixed forests with cuttings
Birch and aspen forests
Treeless land
Sike: Sphagnum bogs
Mountain tundra and rocks
Forest gain on agricultural lands
Water surface
Forest cuttinggs and
other disturbances
Agricultural lands
Settlements

Figure 2 Topography (a) and vegetation types (b) of the Votkinsk reservoir basin, Russia

Forecast snow and rain precipitations fields computed by the mesoscale Weather Research and Forecasting (WRF) atmospheric model v3.3 have been used as input data for the SWE assessment. The detailed description of the WRF model is presented in (Skamarock et al., 2008). The WRF model is widely used both for research projects and operational forecast services, as well as for high resolution meteorological forecasts in flood warning systems (Kumar et al., 2008; Zhao et al., 2009). 
The WRF model has been run at the computing cluster of Perm State University. The calculations have been done using the ARW dynamical core for the 48-hour period starting at 00 UTC. The model is run with $10 \mathrm{~km}$ grid step and 60 second time step. Output data is provided every 3 hours. The global GFS/NCEP model data are the initial conditions for the WRF model run. The grid size of WRF model was $2000 \mathrm{~km} \times 2000 \mathrm{~km}$. The output data for the period of 15-39 hours from the forecast start were used for further SWE calculations, to provide matching with the timing of precipitation measurements at the weather stations. The results of the cold period (from November to March) total precipitations calculation based on the WRF model are presented at Figure 3.

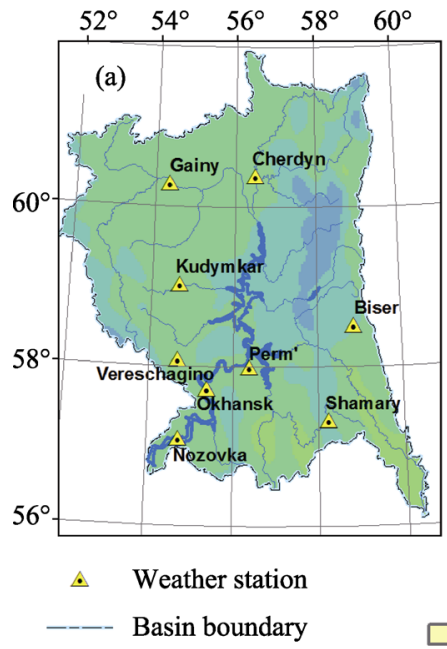

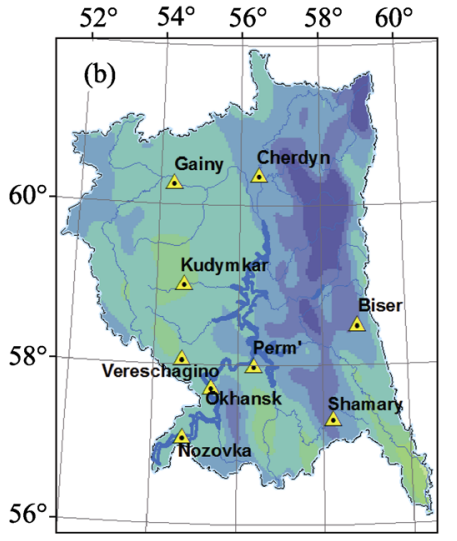

Total precipitation $(\mathrm{mm})$

$100 \quad 150 \quad 200 \quad 250300 \quad 350 \quad 400$ more

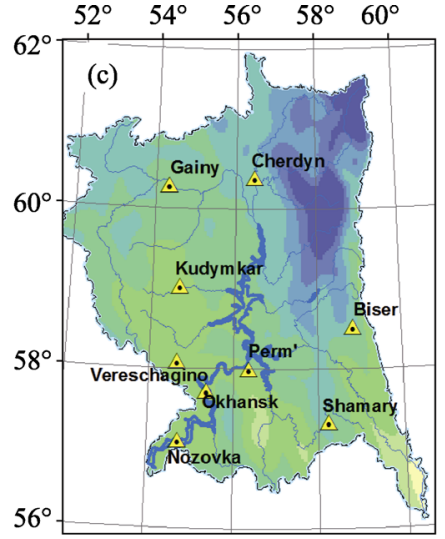

$0 \quad 75150 \quad 300 \mathrm{~km}$

Figure 3 Total precipitation for 2012/13 (a), 2013/14 (b), and 2014/15 (c) cold seasons, calculated by WRF model

\subsection{Main methods}

\subsubsection{Processing of meteorological data}

Ground-based observations data from 34 weather stations located both at the studied watershed and outside it (air temperature and humidity, total and lower cloudiness, daily total precipitations) have been used as input data for snow accumulation and melt model. Simulation of spatial distribution of meteorological variables has been done using interpolation methods with an altitude-dependent-regression. Similar methods for data processing in distributed hydrological models are described by Motoya et al. (2001) and Klok et al. (2002).

Air temperature and humidity interpolation have been based on weather stations observations, using the interpolation method with altitude-dependent-regression. Altitude gradients have been calculated by the WRF model data on temperature and air humidity at the $850 \mathrm{hPa}$ isobaric height per each observation period as well as using digital elevation model.

Wind speed distribution is computed from the WRF model data. To consider the wind speed decrease in a forest, the reducing factors recommended by Koren' (1991) have been introduced. These factors are equal to 0.15 for dark coniferous forests; 0.2 for mixed forests and 0.25 for small-leaved forests.

Daily upward solar radiation during snowmelt season is calculated according to DEM and 
water vapour pressure data using the algorithm implemented in the System for Automatized Geoscientific Analysis (SAGA) software. This algorithm is described in detail by Wilson and Gallant (2000). The influence of total and lower cloudiness, and forest vegetation have been considered with the reducing factors suggested by Kuzmin (1961), and also adapted by Kuchment et al. (2010) for spatially distributed snowpack model. The total and lower cloudiness has been interpolated according to ground-based weather stations. Different reducing factors have also been used to assess total upward solar radiation in different forests types, when the average forest projective cover is 0.7 (Kuzmin, 1961).

The calculation of snow cover albedo has a high uncertainty because the albedo depends on snow surface age, snow depth, snow-covered area, cloudiness and other factors. Freshly fallen snow albedo is $90 \%$ but at the end of a snowmelt period it reduces to $50 \%$ and lower. Besides, the snow albedo in a forest is significantly (at $0.1-0.15$ ) lower than in a treeless area (Melloh et al., 2001). In different snowpack models, the albedo is calculated with empiric dependencies from snow surface age (Wigmosta et al., 1994; Motoya et al., 2001), according to the data about snow cover density changes (Kuchment et al., 2010), or using satellite data. The implementation of physically-based models for albedo calculations, for example (Melloh et al., 2001) for large basins is rather complicated. The approach for albedo calculation considering the main factors influencing its changes proposed by Gordeev (2013) has been modified in the present research. The results of calculation of spatial distribution of snow cover albedo according to the present methodology are presented at Figure 4.

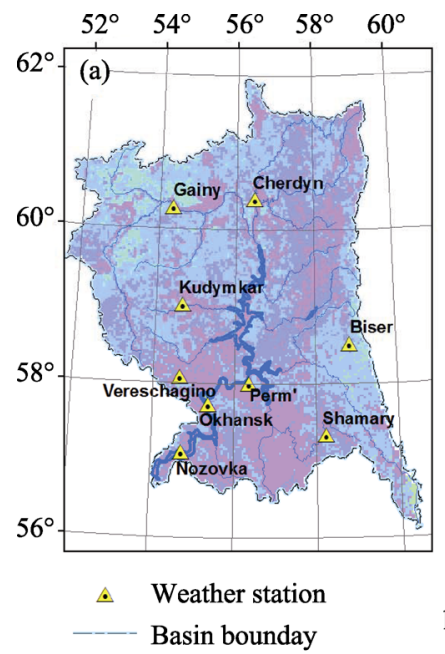

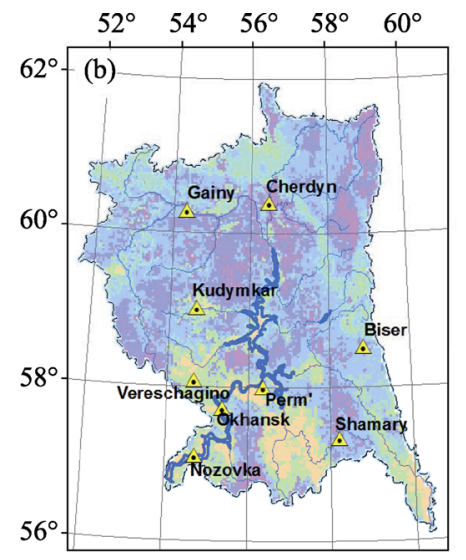

Albedo of snow cover

$\begin{array}{llllllll}\text { less } & 0.5 & 0.6 & 0.65 & 0.75 & 0.7 & 0.8 & \text { more }\end{array}$
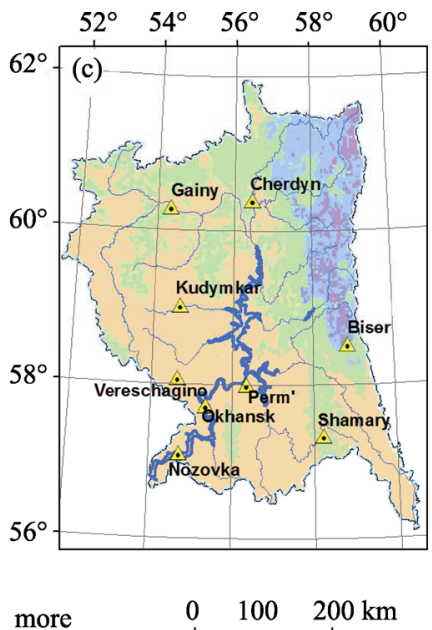

Figure 4 Snow cover albedo dynamics during snowmelt season: a) 03/15/2015; b) 04/15/2015; c) 05/05/2015

\subsubsection{Calculation of snow sublimation in snow accumulation season}

The snowpack losses include snowmelt and snow sublimation. Snowmelt intensity during autumn and winter thaws is calculated with temperature-index method. The degree-day factor has been calculated using calibration considering the land cover type. The influence of solar radiation is minimal during this period, therefore it has not been considered during the calculations.

Snow cover sublimation includes evaporation from the snow surface with intensity de- 
pending on air humidity and wind speed, and sublimation of intercepted snow. The calculation of total snow cover sublimation during cold period is done with the technique described in Karpechko and Bondarik (2010):

$$
E_{\text {sum }}=E_{i}+E
$$

where $E_{i}$ is the sublimation of intercepted snow, $E$ is the sublimation from the snow surface

$$
E_{i}=k \cdot d \cdot L A I \cdot n
$$

where $L A I$ is leaf area index, $d$ denotes an average deficit of saturation air vapour pressure, $n$ signifies the amount of days, $k$ is the empiric reducing factor (accepted to be 0,03 )

$$
E=\left(0.24+0.05 \cdot U_{10}\right) \cdot D \cdot n
$$

where $U_{10}$ is wind speed at $10 \mathrm{~m}$ altitude.

The leaf area index LAI depends on forest vegetation density and forest type. LAI was used to calculate intensity of snow interception for several snow cover models (Pomeroy et al., 1998; Gelfan et al., 2004; Kuchment et al., 2010). LAI has been obtained by MODIS product MOD15A2 (8-day LAI and FPAR). The more detailed description of this product is presented by Myneni et al. (2002). The MODIS data for March, 2015 is used because there was no cloudiness above the studied area at that time.

The total snow evaporation during a cold period estimated according to the above mentioned technique ranges from $10-15 \mathrm{~mm}$ in small-leaved forests to $50 \mathrm{~mm}$ in dark coniferous and pine forests (Figure 5). These values are consistent with field measurements data in neighbouring region (Shutov, 1998). The maximum snow evaporation rate is observed in March because of the low relative air humidity.
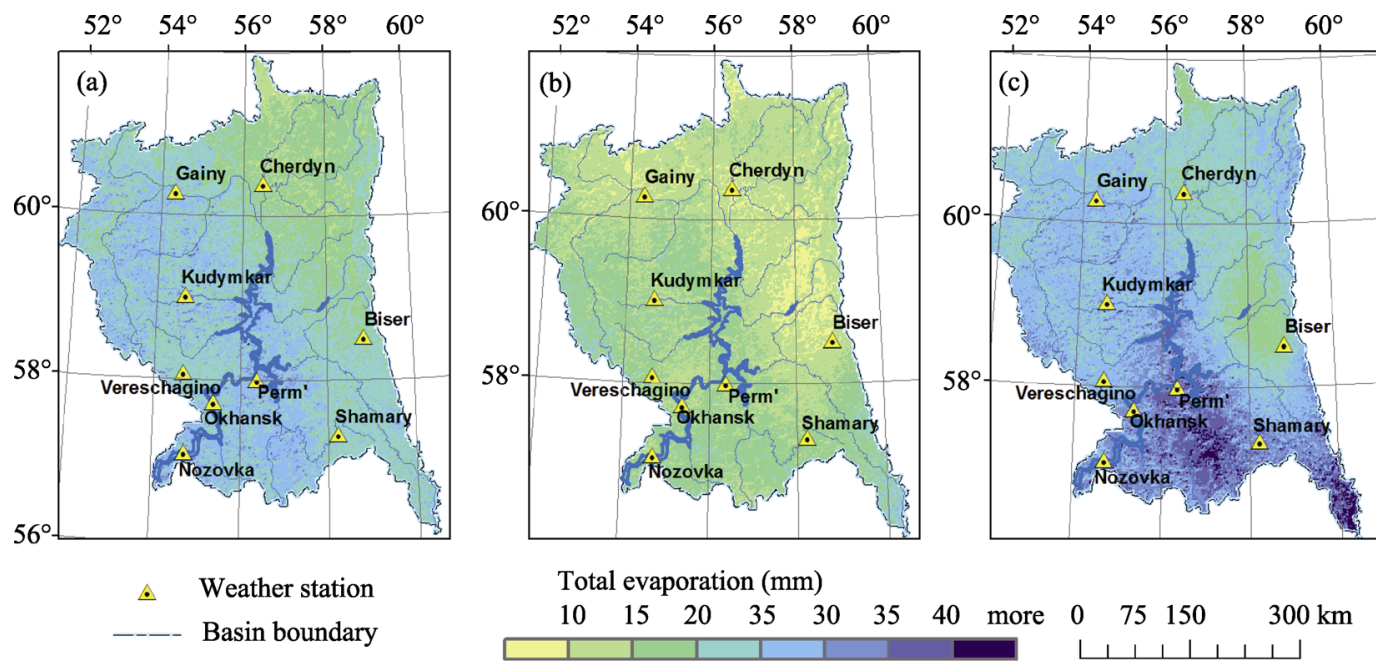

Figure 5 Total snow evaporation in 2012/13 (a), 2013/14 (b) and 2014/15 (c) cold seasons

\subsubsection{Calculation of maximum snow water equivalent}

The maximum SWE is formed at the plain part of the studied area in March and at the mountainous part at the beginning of April. The periods of stable and unstable snow accumulation are observed in the studied basin. Thaws occur infrequently during stable snow accumulation period, from December to February. In this period, the snowpack losses are 
formed mainly due to snow sublimation processes. In the autumn period, thaws are regularly observed. Consequently, snow cover repeatedly appears and disappears at the flat part of the basin, but the steady SWE increase is observed in Ural mountains. The results of the maximum SWE estimation at the studied watershed are shown in Figure 6.

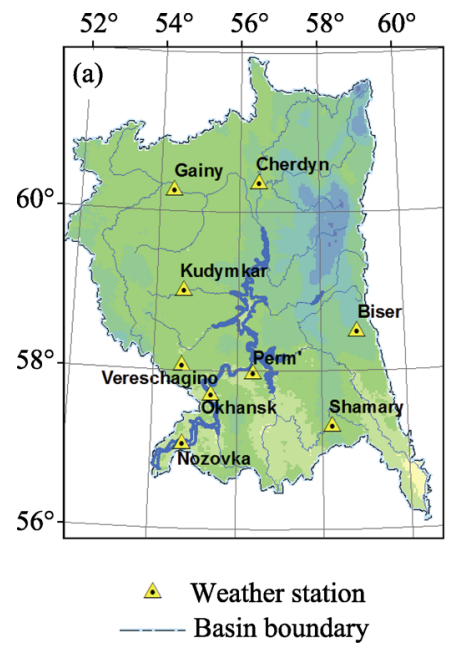

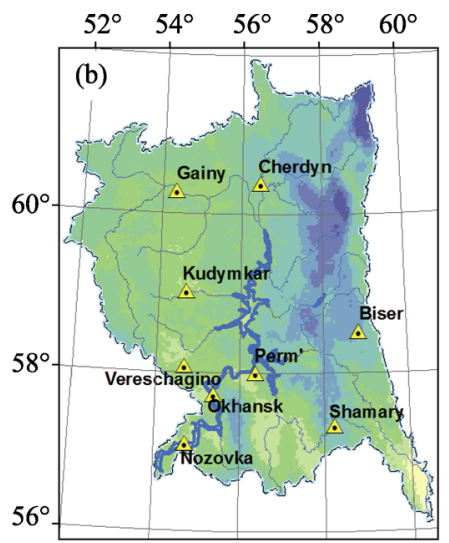

Snow water equivalent $(\mathrm{mm})$ $\begin{array}{llllllll}100 & 150 & 200 & 250 & 300 & 350 & 400 & \text { more }\end{array}$

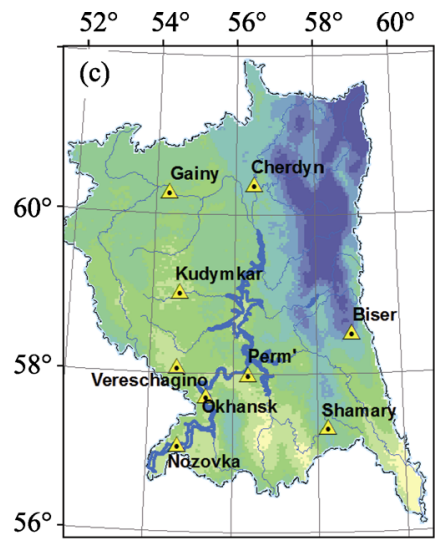

$56^{\circ}$

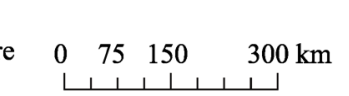

Figure 6 Maximum snow water equivalent during 2012/13 (a), 2013/14 (b) and 2014/15 (c) cold seasons

The spatial distribution of SWE is characterised by substantial spatial heterogeneity and interannual variability, induced by atmospheric circulation peculiarities of each winter season. For example, an intensive zonal atmospheric process was observed in the 2014/15 cold period. Large amount of precipitation fell at the meridional oriented mountain ridges of Northern Ural as a result of the barrier effect. The maximum SWE on the western slopes of the Urals increased to $500 \mathrm{~mm}$ or more. On the contrary, meridional circulation prevailed in the 2012/13 cold period. Therefore, the barrier effect was insignificant and the spatial distribution of precipitation was relatively homogeneous. Zonal atmospheric processes were prevailed also in November and December of 2013, but the meridional circulation was typical for January-February 2014. Thus, the precipitation amounts and snow accumulation rate at these periods differ significantly. In general, the largest SWE was formed on the mountainous part of the watershed in 2015, and on the plain part it was formed in 2014.

\subsubsection{Spring snowmelt modeling}

Simulation of spatial distribution of snowmelt intensity has been implemented by GIS technology, using modified heat balance method, proposed by PP Kuzmin (Kuzmin, 1961). This method allows us to calculate the components of snow cover energy balance based on standard meteorological observations data and simulated incoming solar radiation (including cloudiness influence).

The heat balance equation, neglecting its minor components, is written as follows:

$$
W=W_{R}+W_{A}+W_{E}
$$

where $W_{R}$ denotes radiation balance, $W_{A}$ denotes sensible turbulent heat flux, and $W_{E}$ represents latent heat flux for snow sublimation and from water vapor condensation on the snow surface. 
The radiation component of snowmelt rate $\left(\mathrm{M}_{\mathrm{R}}\right)$ is calculated by:

$$
M_{R}+Q_{s w}-Q_{l s}+Q_{l w}
$$

where $Q_{s w}$ is the short-wave radiation balance, $Q_{l s}$ denotes upward longwave radiation from snow and $Q_{l w}$ is downward long wave radiation. The radiation balance components are calculated as follows (6-8):

$$
\begin{gathered}
Q_{s w}=0.125(Q+q)(1-R)\left(1-0.2 N_{\text {total }}-0.47 N_{\text {lower }}\right) \\
Q_{l s}=\varepsilon \sigma T_{0}^{4} \\
Q_{l w}=\left(\varepsilon \sigma T_{0}^{4}\right)\left(0.62+0.05 e^{0.5}\left(1+0.12 N_{\text {total }}+0.12 N_{\text {lower }}\right)\right.
\end{gathered}
$$

where $Q+q$ represents the short-wave direct and diffuse radiation flux (under clear sky conditions) for the day, $R$ denotes albedo of snow cover, $N_{\text {total }}$ and $N_{\text {lower }}$ are the percentage of total cloudiness and lower level cloudiness respectively, $T_{0}$ represents air absolute temperature, $e$ denotes water vapor pressure at a $2 \mathrm{~m}$ height, $\sigma$ is the Stefan-Boltzmann constant, and $\varepsilon$ signifies the effective emissivity of the snowpack taken equal to 0.99 in this study.

The advective component of snowmelt is determined by the turbulent heat exchange between snow cover and atmosphere, and latent heat flux from condensation of water vapor on the snow surface:

$$
M_{A}=k\left(1+0.544 U_{10}\right)\left(T_{2}-T_{0}+1.75\left(e_{2}-e_{0}\right)\right)
$$

where $U_{10}$ represents wind speed at $10 \mathrm{~m}$ height, $T_{2}$ and $e_{2}$ denotes air temperature and water vapor pressure at $2 \mathrm{~m}$ height, $T_{0}$ is the snow surface temperature, $e_{0}$ is the saturated water vapour pressure at the snow surface temperature. The factor $k$ before formula (9) depends on the model time step; it is assumed to be 0.434 in the case of calculations with 12-hours steps.

Evaporation (E) from snow cover is calculated by the Kuzmin method (Kuzmin, 1961)

$$
E=0.18+0.098 U_{10}\left(e_{2}-e_{0}\right)
$$

Application of energy balance method for simulation of snowmelt requires extensive data processing, which is not always acceptable in operational forecasting. Thereby, we also use a simple temperature-index model for snowmelt simulation. In simple model, the snowmelt intensity is calculated from the average daily temperature taking into account land cover/land use type. We made a comparison of the simulation results for these two models. The output data of both model versions is snow covered area, snow water equivalent and meltwater outflow to the catchment. The results of SWE dynamics simulation during the spring snowmelt period in 2015 are shown in Figure 7.

\section{Results and discussion}

\subsection{Estimation of accuracy of simulated precipitation by the WRF-ARW model}

The reliability of calculation of precipitation amounts in cold period was estimated by comparing the actual and simulated monthly total precipitation at 34 weather stations. The results are presented in Table 1. The following criteria were used to accuracy assessment;

The mean absolute forecast error

$$
\Delta \bar{X}=\sum\left(X_{m}-X_{s}\right) / n,
$$

where $\Delta \bar{X}$ is a mean absolute error of precipitation forecast for the month, $n$ denotes the number of weather stations used in comparison (in this case $n=34$ ), $X_{m}$ signifies monthly 
total precipitation according to the weather station and $X_{S}$ denotes monthly total precipitation according to WRF model data.

Root mean square error of forecast (RMSE)

$$
R M S E=\sqrt{\frac{1}{n} \sum_{i=1}^{n}\left(X_{m}-X_{s}\right)^{2}}
$$
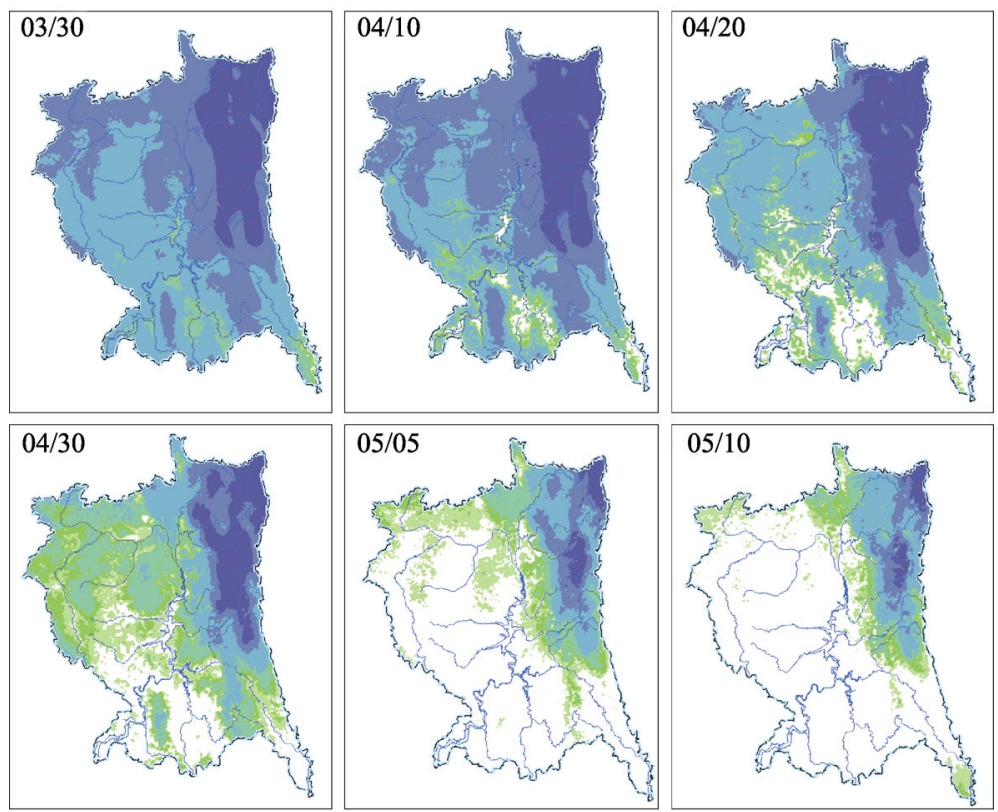

Snow water equivalent $(\mathrm{mm})$

\begin{tabular}{l|llllll}
5 & 25 & 50 & 100 & 200 & 300 & more
\end{tabular}
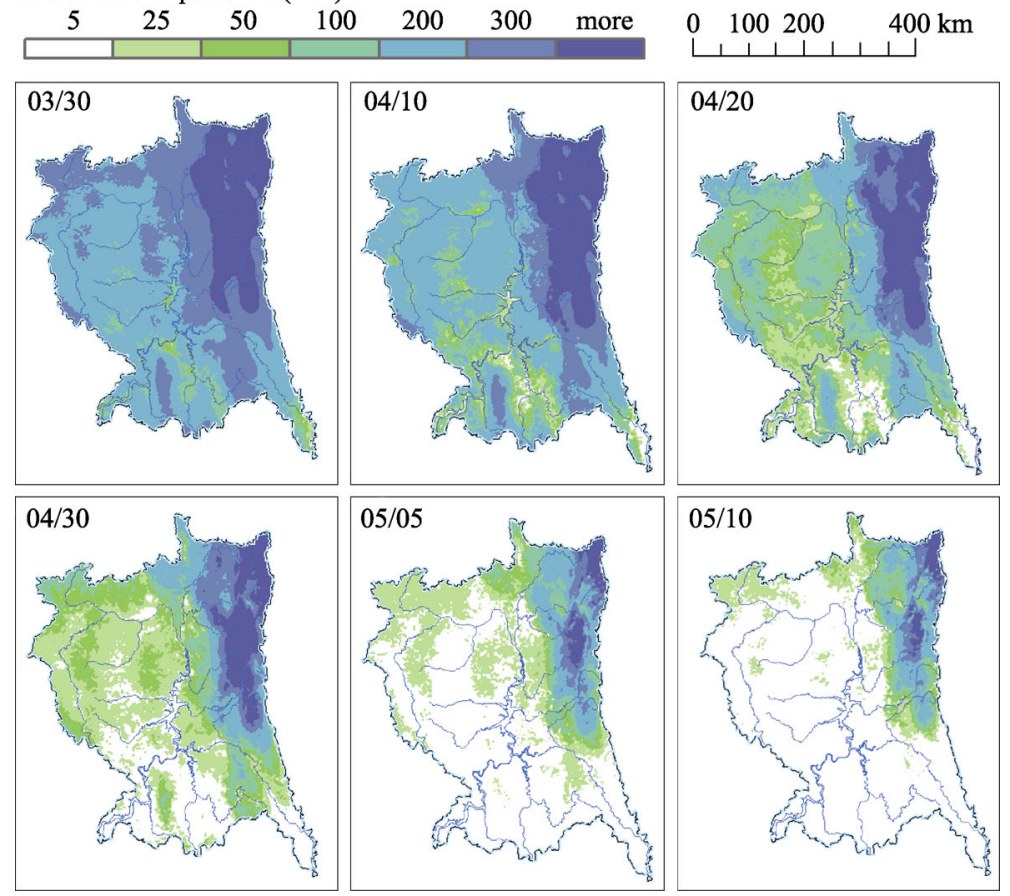

Figure 7 The simulated spatial distribution of SWE in 2014/15 snowmelt season by Kuzmin method (top line) and by temperature-index method (bottom line) 
Comparison of ground-based observations and WRF model forecasts has revealed that the model overestimates the precipitation amount in most cases. Strong systematic overestimation (on average 35\%-50\% along the territory) has been observed in March (for the whole three years) and in February 2013, 2015. Slight overestimation (within 20\%) of simulated precipitation amount is generally observed in November-January. Calculated total precipitation occurred to be 6\% lower than the observed one in February 2014 (Table 1).

Table 1 Estimation of accuracy of simulated precipitation in cold seasons by the WRF-ARW model

\begin{tabular}{|c|c|c|c|c|c|c|}
\hline \multirow{2}{*}{ Parameters } & \multirow{2}{*}{ Year } & \multicolumn{5}{|c|}{ Month } \\
\hline & & November & December & January & February & March \\
\hline \multirow[t]{3}{*}{$X_{m}$} & $2012 / 13$ & 61.8 & 29.5 & 33.8 & 15.1 & 50.5 \\
\hline & $2013 / 14$ & 65.0 & 59.5 & 39.6 & 34.7 & 44.9 \\
\hline & $2014 / 15$ & 24.1 & 45.1 & 42.3 & 28.6 & 17.0 \\
\hline \multirow[t]{3}{*}{$X_{s}$} & $2012 / 13$ & 65.0 & 32.6 & 33.9 & 21.9 & 66.6 \\
\hline & $2013 / 14$ & 64.7 & 62.5 & 44.0 & 32.2 & 67.2 \\
\hline & $2014 / 15$ & 28.0 & 54.0 & 49.2 & 43.0 & 27.8 \\
\hline \multirow[t]{3}{*}{$\Delta \bar{X}$} & $2012 / 13$ & 10.0 & 4.9 & 5.2 & 7.7 & 17.8 \\
\hline & $2013 / 14$ & 12.0 & 9.3 & 7.2 & 6.2 & 24.1 \\
\hline & $2014 / 15$ & 5.8 & 9.3 & 9.5 & 15.0 & 11.1 \\
\hline \multirow[t]{3}{*}{$R M S E$} & $2012 / 13$ & 12.1 & 6.9 & 6.2 & 8,6 & 21.1 \\
\hline & $2013 / 14$ & 15.4 & 11.6 & 9.1 & 8.7 & 27.0 \\
\hline & $2014 / 15$ & 6.6 & 11.1 & 12.0 & 16.1 & 12.5 \\
\hline \multirow[t]{4}{*}{$R M S E / X_{m}, \%$} & $2012 / 13$ & 20.0 & 23.0 & 18.0 & 57 & 42.0 \\
\hline & $2013 / 14$ & 23.0 & 20.0 & 23.0 & 25 & 60.0 \\
\hline & $2014 / 15$ & 27.0 & 25.0 & 28.0 & 56 & 73.0 \\
\hline & $2014 / 15$ & 6.1 & 10.7 & 10.8 & 16.1 & 11.2 \\
\hline
\end{tabular}

RMSE for the calculation of monthly total precipitation by the WRF model is within $18 \%-31 \%$ (in most cases) from the average precipitation amount measured by ground-based weather stations. These results can be considered satisfactory as calculation errors value is close to measurement errors in snow precipitation at the weather stations. Solid precipitation assessment at weather stations is known to be $20 \%-30 \%$ less than the actual due to the snow blowing from a precipitation gauge. RMSE increases significantly at the end of the cold period (February-March). Overestimation of simulated precipitation amounts achieves $35 \%-50 \%$ on average, and to $80 \%-100 \%$ at some weather stations. The model overestimates amount of large-scale and local heavy precipitation.

The largest difference between model and observed precipitation amount is typical for the weather stations located at a lower relief type, in deep river valleys in particular. At the same time, the total model precipitation exceeds the observed one less than $20 \%$ for weather stations located at highlands. The spatial resolution of forecast data explains these deviations. The WRF model with a $10 \mathrm{~km}$ grid step smooths the spatial distribution of precipitation without consideration of the mesoscale forms of terrain. However, the areas with maximum precipitation accumulation due to the barrier effect of meridionally oriented mountain ridges are well identified even with this grid step. The model does not reduce precipitations in river 
valleys, in comparison with the neighbourhood highlands if valleys width is lower than $5 \mathrm{~km}$. The decrease of a grid step up to $3-5 \mathrm{~km}$ is able to remove this disadvantage but additional computing resources should be used to run a high resolution model for long time period.

The spatial distribution of precipitation during cold period is characterised by significant similarities. The precipitation amount increases always with the altitude, and other spatial distribution peculiarities during every winter season depend on circulation conditions. When zonal processes prevail, the barrier effect of highlands and mountains is stronger and precipitation is distributed more unevenly. Thus, according to the WRF model data more than $500 \mathrm{~mm}$ of precipitation fell on axis part of the Northern Ural, whereas less than $100 \mathrm{~mm}$ of precipitation observed to the east of the mountain ridge. When the zonal circulation was reduced (for example, in 2012-2013 winter season), the barrier effect of mountains is smoothed and precipitation is distributed more evenly.

\subsection{Accuracy assessment of snow water equivalent simulation}

The model SWE at the Votkinsk reservoir basin is validated against the SWE field measurements data along the forest and clearing routes of 24 weather stations. To compare with the snow survey data, the simulated SWE was extracted from the model grid cell. The spatial distribution of these cells corresponds to the snow surveys routes of weather stations. Reliability of SWE estimation has been checked by both the method suggested by Kuzmin and by temperature-index method. The average SWE according to forest and clearing snow survey routes and its RMSE calculation are presented in Figure 8, whereas Figure 9 presents the comparison of measured and simulated SWE at individual weather stations.
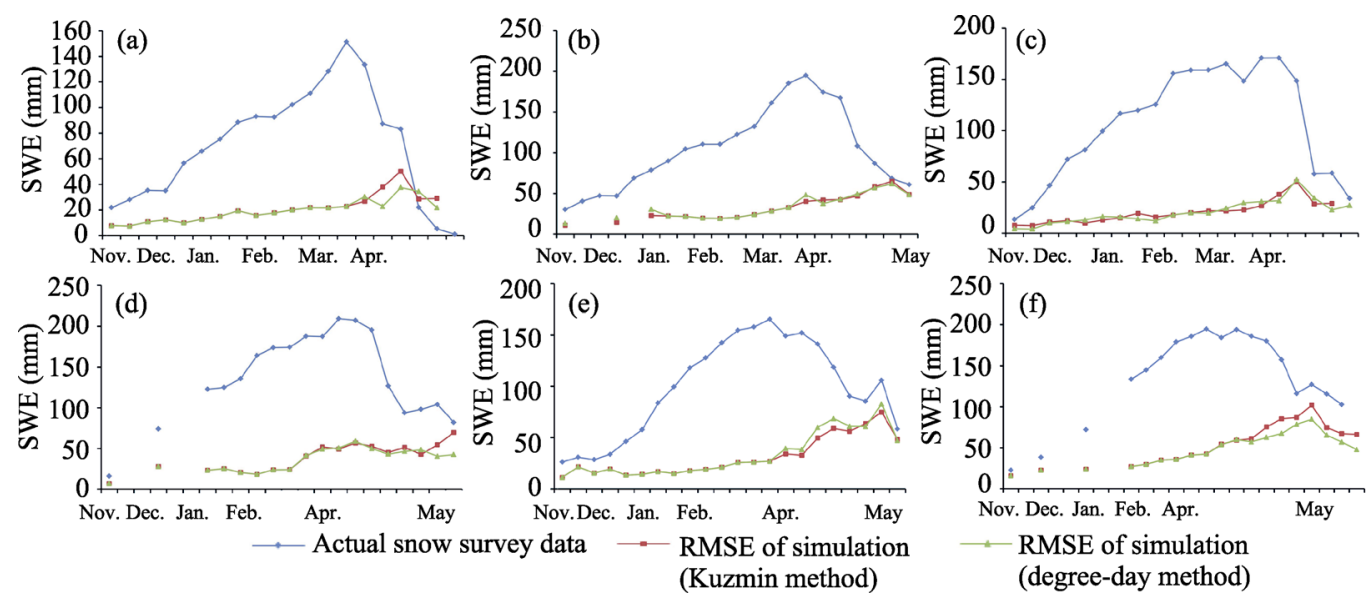

Figure 8 Accuracy assessment of simulated SWE seasonal dynamics: a) - 2012/13, treeless areas; b) - 2012/13, forest; c) - 2013/14, treeless areas; d) - 2013/14, forest; e) - 2014/15, treeless areas; d) - 2014/15, forest

The increase of the absolute calculation error should be mentioned during the snow accumulation period. However, RMSE did not exceed 25\% from the observed SWE (except one case in 2015) during the maximum snow accumulation period (in March). This RMSE value may be considered satisfactory since the snow survey data are not considered to be representative (particularly in the mountainous part of the catchment). RMSE of snow water equivalent estimation increases significantly during the spring snowmelt since local factors of snow redistribution begin to effect. 
When calculating the spring snowmelt by Kuzmin method there is an underestimation of snowmelt intensity in forests but it is overestimated in open terrain. On the contrary, we observed the overestimation of snowmelt intensity in forests when using the temperature-index method. In general, the results of both calculation methods are comparable.

The difference of observed and measured SWE at the studied basin is systematic in some cases. For example, the systematic overestimation of SWE was observed in February-March 2015 that was caused by the total precipitation overestimation by the WRF model at that period. The greatest divergence between the measured and simulated SWE are typical for the mountainous areas (Figure 9). Snow survey data in the mountainous part of the Urals obtained in deep river valleys are not representative for the neighbouring territory.
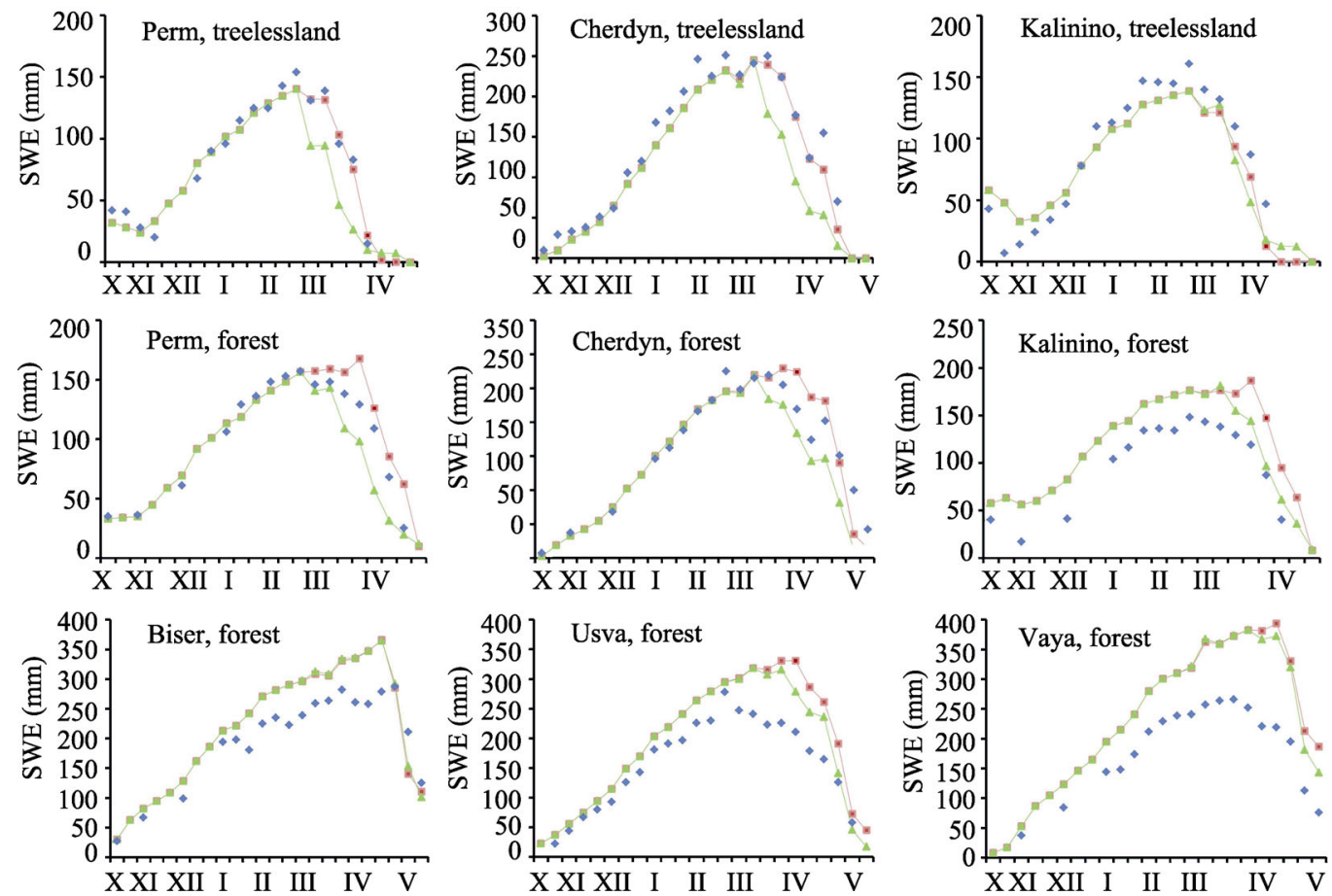

Figure 9 Seasonal dynamics of measured (blue points), simulated using Kuzmin method (red line) and simulated using degree-day method (green line) SWE (in $\mathrm{mm}$ ) at selected stations within the study area for the season from October 2014 to May 2015

\subsection{Accuracy estimation of snow-covered area simulation during snowmelt period}

The representativeness and reliability of SWE measurements decrease and their frequency becomes insufficient during spring snowmelt period. Therefore, the satellite data about a snow-covered area (SCA) become necessary for operational monitoring of snowmelt. The main source of SCA satellite measurements is the Earth Observing System MODIS radiometer. The algorithm of snow cover mapping by MODIS data (ATBD-MOD10) is based on a Normalized Differential Snow Index NDSI (Hall et al., 2001). ATBD-MOD10 algorithm has been tested by authors while comparing a huge amount of MODIS images with LANDSAT satellite data. The threshold value of NDSI for identifying snow covered area (SCA) is recommended to be 0.4. According to the algorithm developers, the accuracy of SCA estimation ranges from $90 \%$ to $98 \%$ in dependence on a season and vegetation type 
(Hall and Riggs, 2007).

Dense forest vegetation complicates snow cover identified by ATBD-MOD10 algorithm. Snow cover reliably identified only for deciduous forests. To estimate the SCA in the mixed and coniferous forests, it needs to use other NDSI threshold values. Regional NDSI threshold values have been calculated while comparing MODIS and LANDSAT satellite images. The threshold regional value for woodless areas is set to 0.35 ; and for forest areas it is 0.1 . The MCD12Q1 (Land Cover Type) data was used to create forest mask of studied basin.

The comparison of the SCA maps created using standard and modified algorithms is presented in Figure 10. Satellite data have been received on April 3, 2015 when the entire watershed was covered by snow. The SCA estimated using the modified algorithm was about $96 \%$, but it decreased to $78 \%$ according to the ATBD-MOD10 data. Thus, the change of the threshold values recommended in ATBD-MOD10 increase the accuracy of SCA estimation by MODIS satellite data.

The SCA estimated by the modified algorithm was compared to the simulated SCA (Figure 11). The difference between the actual and estimated SCA does not exceed $10 \%$ in most cases. The SCA estimated using Kuzmin method turned to be slightly overestimated in 2013 and 2015, whereas the SCA calculated by temperature-index method often turns to be underestimated. In general, it is difficult to determine a method providing more accurate results.

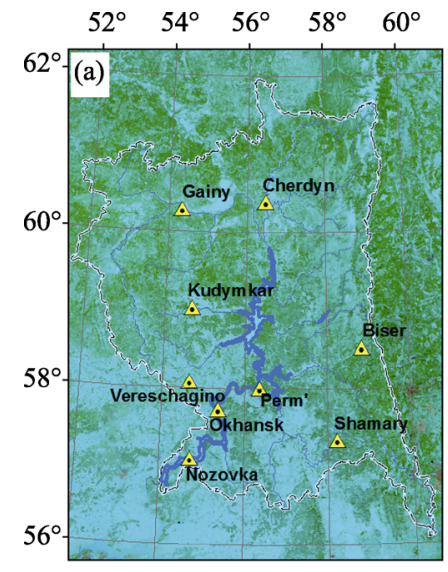

$\triangle \quad$ Weather stattion

--_- Basin boundary
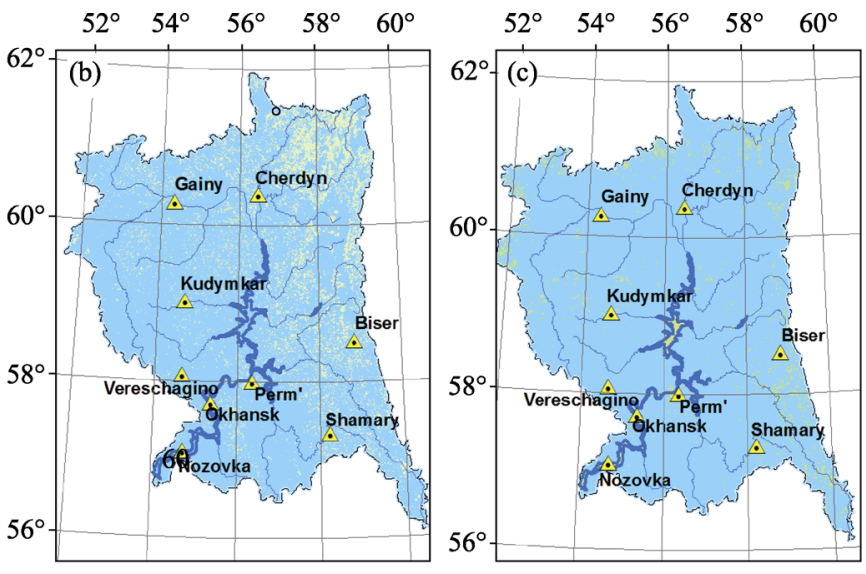

$56^{\circ}$

Land surface Snow cover
Cloudiness

$0 \quad 75 \quad 150$

Figure 10 Assessment of snow-covered area by MODIS data of April 3, 2015: a) RGB bands 7-2-1; b) Snow-covered area calculated by ATBD-MOD10; c) Snow-covered area calculated by modified algorithm
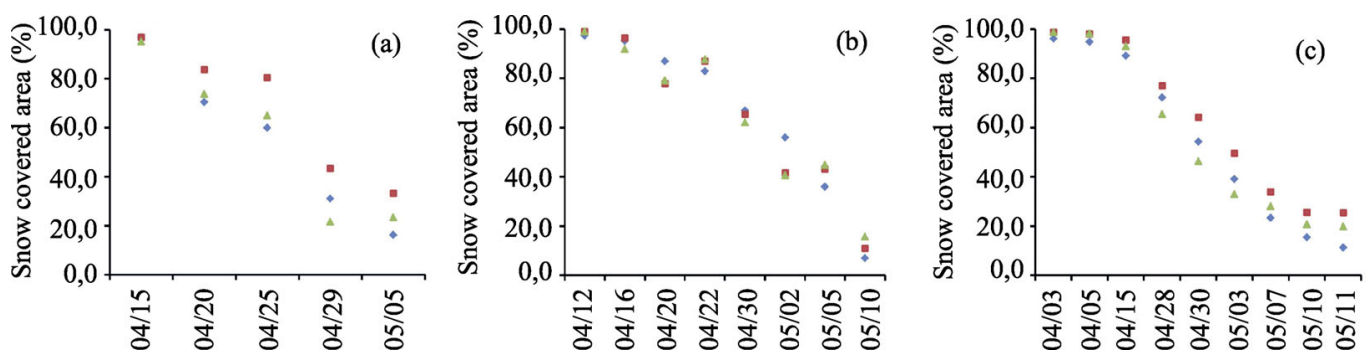

Figure 11 MODIS-observed (blue symbol), simulated by the Kuzmin method (red symbol) and simulated by degree-day method (green symbol) snow-covered area for the 2013 (a), 2014 (b) and 2015 (c) snowmelt seasons 


\section{Conclusion}

The combination of ground-based observations, satellite data and mesoscale numerical weather forecast models is a promising approach to estimate SWE spatial distribution at large watersheds with mountainous areas and sparse observation networks. The results of these studies show the relevance and reliability of the presented method application for the Votkinsk Reservoir basin and the advantages of its further development at neighbouring or similar regions. The forecast precipitation fields by the WRF model have been used to estimate the spatial distribution of the SWE. The significant errors revealed while comparing field measurements data to model results are caused by local features of snow survey route locations.

The use of the digital elevation model and MODIS data (vegetation cover maps and leaf area index) allows to simulate SWE spatial distribution with high resolution considering the influence of landscape conditions of snow accumulation processes. The suggested methodology realised on a GIS-technology basis provides users with visual results.

The algorithm for snow cover identification by MODIS data (ATBD-MOD10) has been modified to be used for forest areas. It allows us to decrease errors when estimating the SCA by satellite data and to use MODIS data for the model validation more efficiently.

\section{Acknowledgements}

We would like to thank the staff of Center of parallel and distributed computing of Perm State University for their great help in WRF model installation and maintenance. We would also like to thank the personnel of Perm Center for hydrometeorology and environmental monitoring for their assistance in getting snow field measurements (snow survey) data.

\section{References}

Addor N, Jaun S, Fundel F et al., 2011. An operational hydrological ensemble prediction system for the city of Zurich (Switzerland): Skill, case studies and scenarios. Hydrology and Earth System Sciences, 15: 2327-2347.

Bl“oschl G, 1999. Scaling issues in snow hydrology. Hydrological Processes, 13: 2149-2175.

Carroll S S, Cressie N, 1996. A comparison of geostatistical methodologies used to estimate snow water equivalent. Water Resources Bulletin, 32: 267-278.

Chang A T C, Rango A, 2000. Algorithm Theoretical Basis Document for the AMSR-E Snow Water Equivalent Algorithm, Version 3.1. Greenbelt, MD, USA, NASA Goddard Space Flight Center, 49 pp.

Elder K, Rosenthal W, Davis R, 1998. Estimating the spatial distribution of snow water equivalence in a montane watershed. Hydrological Processes, 12: 1793-1808.

Erxleben J, Elder K, Davis R, 2002. Comparison of spatial interpolation methods for estimating snow distribution in the Colorado Rocky Mountains. Hydrological Processes, 16: 3627-3649.

Garen D C, Marks D, 2005. Spatially distributed energy balance snowmelt modelling in a mountainous river basin: Estimation of meteorological inputs and verification of model results. Journal of Hydrology, 315: 126-153.

Gelfan A N, Pomeroy J W, Kuchment L S, 2004. Modeling forest cover influences on snow accumulation, sublimation, and melt. Journal of Hydrometeorology, 5: 785-803.

Georgakakos K P, Graham N E, Modrick T M et al., 2014. Evaluation of real-time hydrometeorological ensemble prediction on hydrologic scales in northern California. Journal of Hydrology, 519: 2978-3000.

Gordeev I N, 2013. Simulation of the dynamics of snow albedo during the snowmelt in the basin of the Yenisei River. Earth's Cryosphere, 17: 47-50. (in Russian)

Hall D K, Riggs G A, 2007. Accuracy assessment of the MODIS snow products. Hydrological Processes, 21: 1534-1547. 
Hall D K, Riggs G A, Salomonson V V et al., 2002. MODIS snow-cover products. Remote Sensing of Environment, 83: 181-194.

Karpechko Yu V, Bondarik N L, 2010. Hydrological role of agricultural \& wood activities in the taiga zone of European Russian north. Karelian Scientific Center of RAS: Petrozavodsk. (in Russian)

Klok E J, Jasper K, Roelofsma K P et al., 2002. Distributed hydrological modelling of a heavily glaciated Alpine river basin. Hydrological Sciences Journal des Sciences Hydrologiques, 46(4): 553-570.

Koren' V I, 1991. Mathematical Models in River Runoff Forecasting. Leningrad: Gidrometeoizdat Publishers. (in Russian)

Kuchment L S, Gelfan A N, Demidov V N, 2000. A distributed model of runoff generation in the permafrost regions. Journal of Hydrology, 240: 1-22.

Kuchment L S, Romanov P Yu, Gelfan A N et al., 2010. Use of satellite-derived data for characterization of snow cover and simulation of snowmelt runoff through a distributed physically based model of runoff generation. Hydrology and Earth System Sciences, 14: 339-350.

Kumar S V, Peters-Lidard C D, Eastman J L et al., 2008. An integrated high-resolution hydrometeorological modeling testbed using LIS and WRF. Environmental Modelling and Software, 23: 169-181.

Kunstmann H, Stadler C, 2005. High resolution distributed atmospheric-hydrological modelling for Alpine catchments. Journal of Hydrology, 314: 105-124.

Kuzmin P P, 1961. The Process of Snow Cover Melting. Leningrad: Gidrometeoizdat Publishers. (in Russian)

Lehning M, Völksch Ingo I, Gustafsson D et al., 2006. ALPINE3D: A detailed model of mountain surface processes and its application to snow hydrology. Hydrological Processes, 20: 2111-2128.

Lopez-Moreno J I, Nogues-Bravo D, 2006. Interpolating local snow depth data: An evaluation of methods. Hydrological Processes, 20: 2217-2232.

Marks D, Domingo J, Susong D et al., 1999. A spatially distributed energy balance snowmelt model for application in mountain basins. Hydrological Processes, 13: 1935-1959.

Melloh R A, Hardy J P, Bailey R N et al., 2001. An efficient snow albedo model for the open and sub-canopy. Hydrological Processes, 16: 3571-3584.

Motoya K, Yamazaki T, Yasuda N, 2001. Evaluating the spatial and temporal distribution of snow accumulation, snowmelts and discharge in a multi basin scale: An application to the Tohoku Region, Japan. Hydrological Processes, 15: 2101-2129.

Myneni R B, Hoffman S, Knyazikhin Y et al., 2002. Global products of vegetation leaf area and fraction absorbed PAR from year one of MODIS data. Remote Sensing of Environment, 83: 214-231.

Nosenko O A, Dolgih N A, Nosenko G A, 2006. Snow cover in the Central European Russia under the data derived from AMSR-E and SSM/I. In: Recent Problems of the Land Surface Remote Sensing from the Space: Physical Basis, Technologies of Monitoring of the Environment and Dangerous Phenomena, "Azbuka-2000", Moscow, Russia, 296-301. (in Russian)

Pomeroy J W, Gray D M, Shook K R et al., 1998. An evaluation of snow accumulation and ablation processes for land surface modelling. Hydrological Processes, 12: 2339-2367.

Quéno L, Vionnet V, Dombrowski-Etchevers I et al., 2016. Snowpack modelling in the Pyrenees driven by kilometric-resolution meteorological forecasts. Cryosphere, 10: 1571-1589.

Shutov V A, 1998. Investigations, analysis and modeling of different scaled spatial variability of snow storage. Izvestiya - Akademiya Nauk, Seriya Geograficheskaya, 1: 122-132. (in Russian)

Skamarock W, Klemp J, Dudhia J et al., 2008. A description of the Advanced Research WRF version 3. NCAR Tech., Note NCAR/TN-475+STR.

Tarboton D G, Luce C H, 1996. Utah energy balance snow accumulation and melt model (UEB): Computer model technical description and users guide. Utah Water Research Laboratory and USDA Forest Service Intermountain Research Station, Logan, Utah.

Verbunt M, Zappa M, Gurtz J et al., 2006. Verification of a coupled hydrometeorological modelling approach for alpine tributaries in the Rhine basin. Journal of Hydrology, 324: 224-238.

Wigmosta M S, Vail L W, Lettenmaier D P, 1994. A distributed hydrology-vegetation model for complex terrain. Water Resources Research, 30(6): 1665-1679.

Wilson, J P, Gallant J C, 2000. Terrain Analysis: Principles and Applications. New York: John Wiley \& Sons.

Zhao Q, Liu Z, Ye B et al., 2009. A snowmelt runoff forecasting model coupling WRF and DHSVM. Hydrology and Earth Systems Sciences, 13: 925-940. 